\title{
Lower dementia risk with anticoagulation and ablation in patients with atrial fibrillation
}

\author{
Daehoon $\mathrm{Kim}^{1 \dagger}$, Pil-Sung Yang ${ }^{2 \dagger}$ and Boyoung Joung ${ }^{1 *}$ (D)
}

\begin{abstract}
Atrial fibrillation (AF), the most common cardiac arrhythmia in the elderly population, has been associated with an impairment of cognitive function and an increased risk of dementia. Even though there does not appear to be solid evidence that any specific treatment prevents or delays AF-associated cognitive decline, evidence is accumulating regarding the possible treatment strategies for preventing dementia. Oral anticoagulation, especially non-vitamin $\mathrm{K}$ antagonist oral anticoagulants rather than warfarin use, has been suggested to be associated with reduced risk of dementia. Successfully maintaining sinus rhythm using catheter ablation might be also helpful in preventing subsequent dementia in patients with AF. In this review, we critically appraise the proposed treatment strategies for preventing AF-associated cognitive decline.
\end{abstract}

Keywords: Atrial fibrillation, Dementia, Anticoagulants, Ablation

\section{Introduction}

Atrial fibrillation (AF) is the most common sustained cardiac arrhythmia, especially in elderly population [1-4]. AF increases the risk of mortality and morbidity resulting from stroke, congestive heart failure, and impaired quality of life, explaining its enormous socioeconomic and healthcare implications [3]. The age distribution of AF among populations of developed countries is predicted to shift in coming years, with an expected increase in prevalence among the elderly. The fact that AF prevalence has progressively risen 2.10 -fold over the past 10 years in Korea, with an increase to $8.15 \%$ in patients $\geq 80$ years of age, supports this predicted progression [4].

There are approximately 50 million people living with dementia worldwide, and this number is expected to increase to 152 million by 2050, with a rising aged population $[5,6]$. Although the pathophysiological

*Correspondence: cby6908@yuhs.ac

†Daehoon Kim and Pil-Sung Yang have contributed equally to this work ${ }^{1}$ Division of Cardiology, Department of Internal Medicine, Severance Cardiovascular Hospital, Yonsei University College of Medicine, 50-1 Yonsei-ro, Seodaemun-gu, Seoul 03722, Republic of Korea

Full list of author information is available at the end of the article mechanisms of dementia are largely unknown, evidence is accumulating that AF may contribute to the development of cognitive dysfunction and dementia, even without overt stroke [7-11]. In this review, we summarize the evidence linking AF to dementia and critically appraise potential treatment strategies for preventing AF-associated cognitive decline.

\section{AF and dementia}

\section{AF linked to increased risk of dementia}

The Rotterdam Study demonstrated that cognitive dysfunction was approximately twice as common in subjects with AF as in those without [10]. However, the cross-sectional design of that study precluded definitive conclusions regarding a causal relationship. Since then, several longitudinal studies have investigated the association between $\mathrm{AF}$ and incident dementia, with inconsistent results: some studies found that AF was associated with an increased risk of cognitive decline or dementia $[7,9,11]$, whereas others found no association $[12,13]$. Data regarding the association of atrial fibrillation with risk of dementia are summarized in Table 1.

Kim et al. investigated the association of incident $\mathrm{AF}$ with the development of incident dementia was original author(s) and the source, provide a link to the Creative Commons licence, and indicate if changes were made. The images or other third party material in this article are included in the article's Creative Commons licence, unless indicated otherwise in a credit line to the material. If material is not included in the article's Creative Commons licence and your intended use is not permitted by statutory regulation or exceeds the permitted use, you will need to obtain permission directly from the copyright holder. To view a copy of this licence, visit http://creativecommons.org/licenses/by/4.0/. 
Table 1 Association between atrial fibrillation and dementia

\begin{tabular}{|c|c|c|c|c|c|c|}
\hline \multirow[t]{2}{*}{ Study (Year of publication) } & \multirow{2}{*}{$\begin{array}{l}\text { Follow-up } \\
\text { duration } \\
\text { (years) }\end{array}$} & \multirow{2}{*}{$\begin{array}{l}\text { Age (years) of } \\
\text { population (mean or } \\
\text { median) }\end{array}$} & \multirow[t]{2}{*}{ Types of dementia } & \multicolumn{2}{|c|}{ Incidence of dementia } & \multirow{2}{*}{$\begin{array}{l}\text { Increased dementia risk } \\
\text { for AF (OR or HR [ } 95 \% \\
\text { CI]) }\end{array}$} \\
\hline & & & & $\overline{A F}$ & No AF & \\
\hline \multirow{3}{*}{$\begin{array}{l}\text { Ott et al. [10] } \\
\text { (1997) }\end{array}$} & \multirow[t]{3}{*}{ Cross-sectional } & \multirow[t]{3}{*}{67.9} & All-cause & - & - & $2.3(1.4-3.7)$ \\
\hline & & & $A D$ & - & - & $1.8(1.0-3.3)$ \\
\hline & & & $\mathrm{VaD}$ & - & - & $1.9(0.6-5.5)$ \\
\hline \multirow[t]{4}{*}{ Bunch et al. [7] (2010) } & \multirow[t]{4}{*}{5.3} & \multirow[t]{4}{*}{60.6} & All-cause & $3.3 \%$ & $1.3 \%$ & 1.44 \\
\hline & & & $A D$ & $1.5 \%$ & $0.7 \%$ & 1.06 \\
\hline & & & SD & $1.6 \%$ & $0.6 \%$ & 1.39 \\
\hline & & & $\mathrm{VaD}$ & $0.9 \%$ & $0.3 \%$ & 1.73 \\
\hline \multirow[t]{2}{*}{ Dublin et al. [11] (2011) } & \multirow[t]{2}{*}{6.8} & \multirow[t]{2}{*}{74.3} & All-cause & $4.8 \% / y r$ & $2.5 \% / y r$ & $1.38(1.10-1.73)$ \\
\hline & & & $A D$ & $3.8 \% / y r$ & $2.0 \% / y r$ & $1.50(1.16-1.94)$ \\
\hline \multirow[t]{2}{*}{ Marengoni et al. [12] (2011) } & \multirow[t]{2}{*}{4.0} & \multirow[t]{2}{*}{78} & All-cause & $7.2 \% / y r$ & $6.4 \% / y r$ & $0.9(0.5-1.7)$ \\
\hline & & & $A D$ & $5.5 \% / y r$ & $5.2 \% / y r$ & $0.8(0.4-1.5)$ \\
\hline \multirow[t]{3}{*}{ Kim et al. [8] (2019) } & \multirow[t]{3}{*}{7.2} & \multirow[t]{3}{*}{71.7} & All-cause & $4.1 \% / y r$ & $2.7 \% / y r$ & $1.52(1.43-1.63)$ \\
\hline & & & $A D$ & $2.2 \% / y r$ & $1.6 \% / y r$ & $1.31(1.20-1.43)$ \\
\hline & & & $\mathrm{VaD}$ & $1.1 \% / y r$ & $0.5 \% / y r$ & $2.11(1.85-2.41)$ \\
\hline
\end{tabular}

$A D$ Alzheimer's disease, $A F$ atrial fibrillation, $C l$ confidence interval, $H R$ hazard ratio, $O R$ odds ratio, $S D$ senile dementia, VaD vascular dementia

assessed in 262,611 dementia- and stroke-free participants aged $\geq 60$ years in the Korea National Health Insurance Service-Senior cohort [8]. The incidence of dementia was 4.1 and 2.7 per 100 person-years in the incident $\mathrm{AF}$ and propensity score matched AF-free groups, respectively. The risk of dementia was significantly increased with a hazard ratio (HR) of 1.52 by incident AF, being analyzed as a time-varying factor to avoid immortal time bias. The association was consistent with even after additionally censoring participants at the time of an incidence of stroke with a HR of 1.27. AF increased the risk of both Alzheimer's disease (HR 1.31) and vascular dementia (HR 2.11) (Fig. 1). Given the relationship between AF and stroke, vascular components may be an obvious contributor to cognitive decline, encompassing both multi-infarct dementia and small vessel disease dementia $[10,14]$. It remains possible that asymptomatic strokes explain the link between AF and dementia [15]. Also, AF has been identified as a risk factor for Alzheimer's disease, the most common type of dementia in overall and AF population [7, $11,14]$. In the majority of cases, the brains of Alzheimers' disease have vascular microinfarcts, white matter lesions, or vessel wall alterations [16]. Increased beta-amyloid and hyperphosphorylated tau reactivity in both infarcted and adjacent brain areas were followed experimentally induced cerebral microemboli in aged rats, suggesting a possible association with Alzheimer's pathophysiology [17]. Vascular risk factors have been linked to risk for Alzheimer's disease in

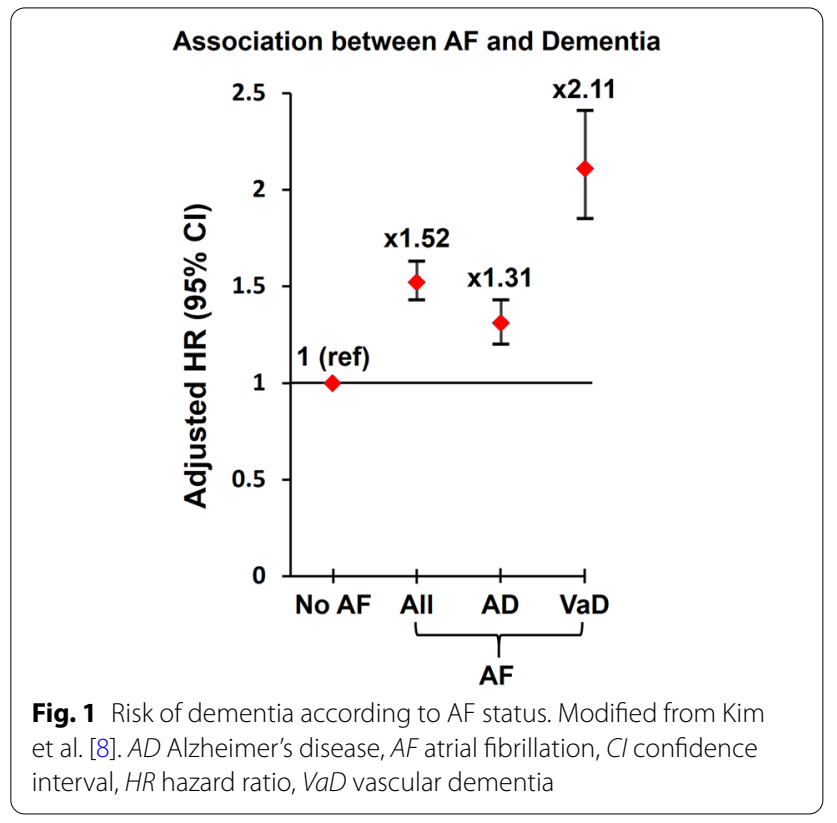

many epidemiological studies $[16,18]$. These evidences have suggested a role for cerebrovascular disease in the onset and progression of Alzheimer's disease, and the vascular attributes might help explain the association between AF and the increased risk of Alzheimer's disease. 


\section{Lower risk of dementia with anticoagulation} Lowering the risk of dementia with oral anticoagulation Evidence is accumulating that the pathogenesis linking AF to dementia is likely multifactorial and silent cerebral infarction including silent stroke plays a central role [19]. The prospective, population-based Rotterdam Scan Study indicated that patients with silent cerebral infarcts visualized on magnetic resonance imaging was associated with doubled risk of dementia compared to those without such lesions [20]. Even though there are no randomized data examining the efficacy of oral anticoagulation preventing dementia in individuals with AF, growing evidence from recent observational data suggests an effectiveness of oral anticoagulant (OAC) to lower the risk of AF-related dementia although preventing dementia is not the primary focus of OAC treatment (Fig. 2) [8, 21-23]. Kim et al. reported that OACs had a preventive effect on dementia with an $\mathrm{HR}$ of 0.61 among patients with incidental AF. In the study, OAC treatment was associated with the decreased risk of both Alzheimer's disease (HR 0.53) and vascular dementia (HR 0.77) [8]. A nation-wide Swedish cohort study by Friberg and Rosenqvist found that patients with AF who received OAC treatment had a $29 \%$ lower risk of dementia than those with AF who were not prescribed OACs [21]. In the study, the benefit of OAC treatment appeared to be more prominent as it had been initiated since the initial diagnosis of AF, suggesting a dose-response relationship between time without $\mathrm{OAC}$ and the development of dementia. The same authors also reported that AF patients with low stroke risk without non-gender risk factors (men with $\mathrm{CHA}_{2} \mathrm{DS}_{2}$-VASc score 0 or women with 1) who use OACs appeared to have lower risk of dementia than those who do not use OACs, suggesting the benefit of OAC even in patients with low risks [22]. An observational study using the UK primary care data found that the use of OAC was associated with a lower risk of new-onset dementia with a HR of 0.90 [23]. The study found a significant association with $\mathrm{OAC}$ use and lower risk of vascular dementia compared to non-OAC use (HR 0.89) whereas there was no statistically significant association between OAC use and risk of Alzheimer's disease. These results support the hypothesis of silent cerebral infarcts contributing to cognitive decline in AF.

\section{Higher benefit of NOAC than warfarin in dementia prevention}

A substudy of the Atrial Fibrillation Clopidogrel Trial With Irbesartan for Prevention of Vascular Events (ACTIVE) trial found that ineffective anticoagulation (a lower time in therapeutic range [TTR]) among warfarin users with AF was related to a higher risk of cognitive dysfunction [24] and dementia [25, 26]. There is a concern about a higher risk of microbleed in patients receiving warfarin treatment, especially in those with labile international normalized ratios. [27] Microbleed may cause chronic cerebral injury and eventually lead to dementia [28]. The non-vitamin $\mathrm{K}$ antagonist oral anticoagulants (NOACs) may mitigate the difficulty of maintaining TTR with a more predictable pharmacokinetic profile, and improved effectiveness, safety, and convenience compared to warfarin. A meta-analysis of the four pivotal phase 3 trials comparing NOACs to warfarin demonstrated that the NOACs were associated with a significant risk reduction in terms of overall stroke and systemic emboli [29], with a greater effect observed in Asians compared to non-Asians [30]. Also with the more predictable pharmacokinetics providing steady therapeutic levels, it has been hypothesized that NOAC could further reduce the risk of dementia relative to warfarin.

\begin{tabular}{|c|c|c|c|c|c|c|c|c|c|c|}
\hline \multirow{2}{*}{$\begin{array}{l}\text { Database } \\
\text { (Year of publication) }\end{array}$} & \multirow{2}{*}{$\begin{array}{l}\text { Patient } \\
\text { Group }\end{array}$} & \multirow{2}{*}{$\begin{array}{c}\text { Type of } \\
\text { Dementia }\end{array}$} & \multicolumn{3}{|c|}{ OAC } & \multicolumn{3}{|c|}{ No OAC } & \multirow{2}{*}{$\mathrm{HR}(95 \% \mathrm{Cl})$} & Dementia Risk \\
\hline & & & $\begin{array}{c}\mathrm{N} \text { of } \\
\text { Patients }\end{array}$ & $\begin{array}{c}\mathrm{N} \text { of } \\
\text { Dementia }\end{array}$ & IR & $\begin{array}{c}\mathrm{N} \text { of } \\
\text { Patients }\end{array}$ & $\begin{array}{c}\mathrm{N} \text { of } \\
\text { Dementia }\end{array}$ & IR & & Favors No OAC \\
\hline \multirow{3}{*}{$\begin{array}{l}\text { Korean NHIS } \\
(2019)\end{array}$} & \multirow{3}{*}{ Overall } & All-cause & & \multirow{3}{*}{ * } & \multirow{3}{*}{ * } & \multirow{3}{*}{7342} & \multirow{3}{*}{ * } & \multirow{3}{*}{ * } & $0.61(0.54-0.68) \mapsto$ & \\
\hline & & $A D$ & 3092 & & & & & & $0.53(0.50-0.63)$ 凹 & \\
\hline & & $\mathrm{VaD}$ & & & & & & & $0.77(0.61-0.97)$ & \\
\hline \multirow{2}{*}{$\begin{array}{l}\text { Swedish national } \\
\text { registers } \\
(21,22 \\
(2018,2019)\end{array}$} & Overall & \multirow{2}{*}{ All-cause } & 80948 & * & * & 80948 & * & * & юr & \\
\hline & & & 20329 & 88 & 0.16 & 17092 & 174 & 0.27 & $0.62(0.48-0.81)$ & \\
\hline \multirow{3}{*}{$\begin{array}{l}\text { UK THIN database }{ }^{23} \ddagger \\
(2020)\end{array}$} & \multirow{3}{*}{ Overall } & All-cause & & 1936 & 1.21 & & 3359 & 1.33 & $0.90(0.85-0.95)$ & \\
\hline & & $A D$ & 35245 & 315 & 0.19 & 49276 & 520 & 0.20 & $0.99(0.86-1.14)$ & $\rightarrow$ \\
\hline & & $\mathrm{VaD}$ & & 482 & 0.30 & & 803 & 0.31 & $0.89(0.80-0.99)$ & \\
\hline
\end{tabular}

Fig. 2 Risk of dementia in patients with AF using oral anticoagulants or not in data from Asian and European populations. AD Alzheimer's disease, IR incidence rate, OAC oral anticoagulant, THIN The Health Improvement Network, VaD vascular dementia. *Not presented in the article. $+\mathrm{CHA}_{2} \mathrm{DS}_{2}-\mathrm{VASC} \mathrm{O}$ (male) or 1 (female). ‡Incidence rates and hazard ratios were inverse probability of treatment weighted 
Data from Asian, European, and North American population-based cohorts regarding the risk of dementia according to oral anticoagulant regimens are summarized in Fig. 3. Two US cohort studies supported the hypothesis with a lower incidence of dementia of NOAC users compared with warfarin users $[31,32]$. In contrast, studies from Swedish and Danish nation-wide cohorts and UK primary care database found comparable incidences of dementia when comparing warfarin and NOAC users [21-23, 33]. A meta-analysis including six randomized controlled trials and two observational studies reported that the use of NOACs was associated with a lower risk of cognitive impairment in comparison to warfarin/acetylsalicylic acid with a pooled HR of 0.80 [34]. Recently, Kim et al. reported that NOAC use was associated with reduced risk of dementia compared with warfarin using Korean nation-wide cohort. [35] This study enrolled new OAC users with non-valvular AF aged $\geq 60$ years in the Korean national health insurance service database and used inverse probability of treatment propensity scoreweighting to compare the rates of dementia between NOAC and warfarin users and to perform pairwise comparisons of three individual NOACs and warfarin. In the Korean nation-wide cohort study, the incidence of dementia was defined as dementia diagnosis (using following International Classification of Disease 10th Revision codes codes: F00 or G30 for Alzheimer's dementia, F01 for vascular dementia, F02 for dementia with other diseases classified elsewhere, and F03 or G31 for unspecified dementia) combined with use of one or more of the following dementia drugs: rivastigmine, galantamine, memantine, or donepezil. The definition of dementia outcome was previously validated with a positive predictive value of $94.7 \%$ [36]. Use of NOACs was associated with a $22 \%$ lesser risk of dementia compared with warfarin. When comparing each individual NOAC with warfarin, the risks of dementia were consistently lower in all individual NOAC groups than in the warfarin group; dabigatran (HR 0.81), rivaroxaban (HR 0.73), and apixaban (HR 0.70). The associations were more prominent among NOAC users on standard dosages. In pairwise comparisons among NOACs, rivaroxaban was associated with decreased dementia risk, compared with dabigatran (HR 0.83). However, considering the induction period for dementia development, the durations of follow-up in those observational studies were relatively short (mean: 1.7 to 5.9 years), which may not be long enough to detect a differential effect of treatment regimen on dementia development. Large longitudinal studies with longer follow-up time are needed to clarify the effect of NOACs on cognitive function, and currently several randomizedcontrolled clinical trials focusing on the impact of NOACs and warfarin on cognitive outcomes in patients with AF have been initiated (ClinicalTrials.gov identifiers NCT01994265 and NCT03061006).

\begin{tabular}{|c|c|c|c|c|c|c|c|c|c|}
\hline \multirow{2}{*}{$\begin{array}{l}\text { Database } \\
\text { (Years of Publication) }\end{array}$} & \multirow{2}{*}{ Patient Group } & \multirow{2}{*}{ Method } & \multicolumn{2}{|c|}{ NOAC } & \multicolumn{2}{|c|}{ Warfarin } & \multirow{2}{*}{ HR $(95 \% \mathrm{Cl})$} & \multicolumn{2}{|c|}{ Dementia Risk } \\
\hline & & & Total & Incidence & Total & Incidence & & Favors NOAC & Favors Warfarin \\
\hline \multirow{5}{*}{$\begin{array}{l}\text { Korean NHIS } 35 \\
\text { (2021) }\end{array}$} & \multirow{2}{*}{ Overall $^{*}$} & PSM & 10193 & 3.49 & 10193 & 5.01 & $0.78(0.68-0.90)$ & 世 & \\
\hline & & $\mathrm{IPW}+$ & 28693 & 3.70 & 24553 & 3.75 & $0.85(0.77-0.93)$ & 田 & \\
\hline & Dabigatran & PSM & 6371 & 4.13 & 6371 & 5.01 & $0.81(0.68-0.97)$ & 曰 & \\
\hline & Rivaroxaban & PSM & 7643 & 3.33 & 7643 & 5.14 & $0.73(0.61-0.88)$ & $\mapsto$ & \\
\hline & Apixaban & PSM & 4948 & 3.94 & 4948 & 6.49 & $0.70(0.56-0.88)$ & $\mapsto$ & \\
\hline \multirow{3}{*}{$\begin{array}{l}\text { Danish national registers }{ }^{33} \\
(2019)\end{array}$} & Age $60-69$ years* & & 6846 & 0.11 & 4332 & 0.12 & $0.92(0.48-1.76)$ & & \\
\hline & Age $70-79$ years* & IPW† & 8126 & 0.64 & 5387 & 0.78 & $0.86(0.68-1.09)$ & & \\
\hline & Age $\geq 80$ years ${ }^{*}$ & & 6339 & 2.16 & 3653 & 1.70 & $1.31(1.07-1.59)$ & & :-1 \\
\hline \multirow{2}{*}{$\begin{array}{l}\text { Swedish national registers }{ }^{21,22} \\
(2018,2019)\end{array}$} & Overall & PSM & 7349 & - & 7349 & - & $0.97(0.67-1.40)$ & $\longmapsto$ & - \\
\hline & Low risk§ & PSM & 2528 & 0.42 & 2528 & 0.74 & $0.47(0.18-1.22)$ & & :1 \\
\hline \multirow{3}{*}{$\begin{array}{l}\text { US MarketScan } \\
\text { + Optum Clinformatics }{ }^{31} \\
\text { (2018) }\end{array}$} & Dabigatran & & 45439 & 1.96 & 45439 & 2.45 & $0.79(0.71-0.88)$ & เө & \\
\hline & Rivaroxaban & PSM & 60178 & 2.22 & 60178 & 2.73 & $0.79(0.63-0.99)$ & $\mapsto$ & \\
\hline & Apixaban & & 30218 & 2.75 & 30218 & 3.26 & $0.73(0.52-1.02)$ & $\longmapsto$ & \\
\hline UK THIN database ${ }^{23}(2020)$ & Overall| & IPW† & 4657 & 1.28 & 12880 & 1.29 & $0.89(0.70-1.14)$ & $\mapsto \Delta$ & $\begin{array}{c}1 \\
\vdots \\
1\end{array}$ \\
\hline
\end{tabular}

Fig. 3 Risk of dementia according to oral anticoagulant regimens in data from Asian, European, and North American populations. Cl confidence interval, HR hazard ratio, IPW inverse probability of treatment weighting, NHIS National Health Insurance Service, PSM propensity score matching, THIN The Health Improvement Network. Incidences were presented as rates per 100 person-years. *Includes dabigatran, rivaroxaban, and apixaban users. tIncidences and hazard ratios were propensity weighted. ‡Types of NOAC and incidences of dementia were not presented in the article. $\S \mathrm{CHA}_{2} \mathrm{DS}_{2}$-VASC $\mathrm{O}$ (male) or 1 (female). IIncludes dabigatran, rivaroxaban, apixaban, and edoxaban users 


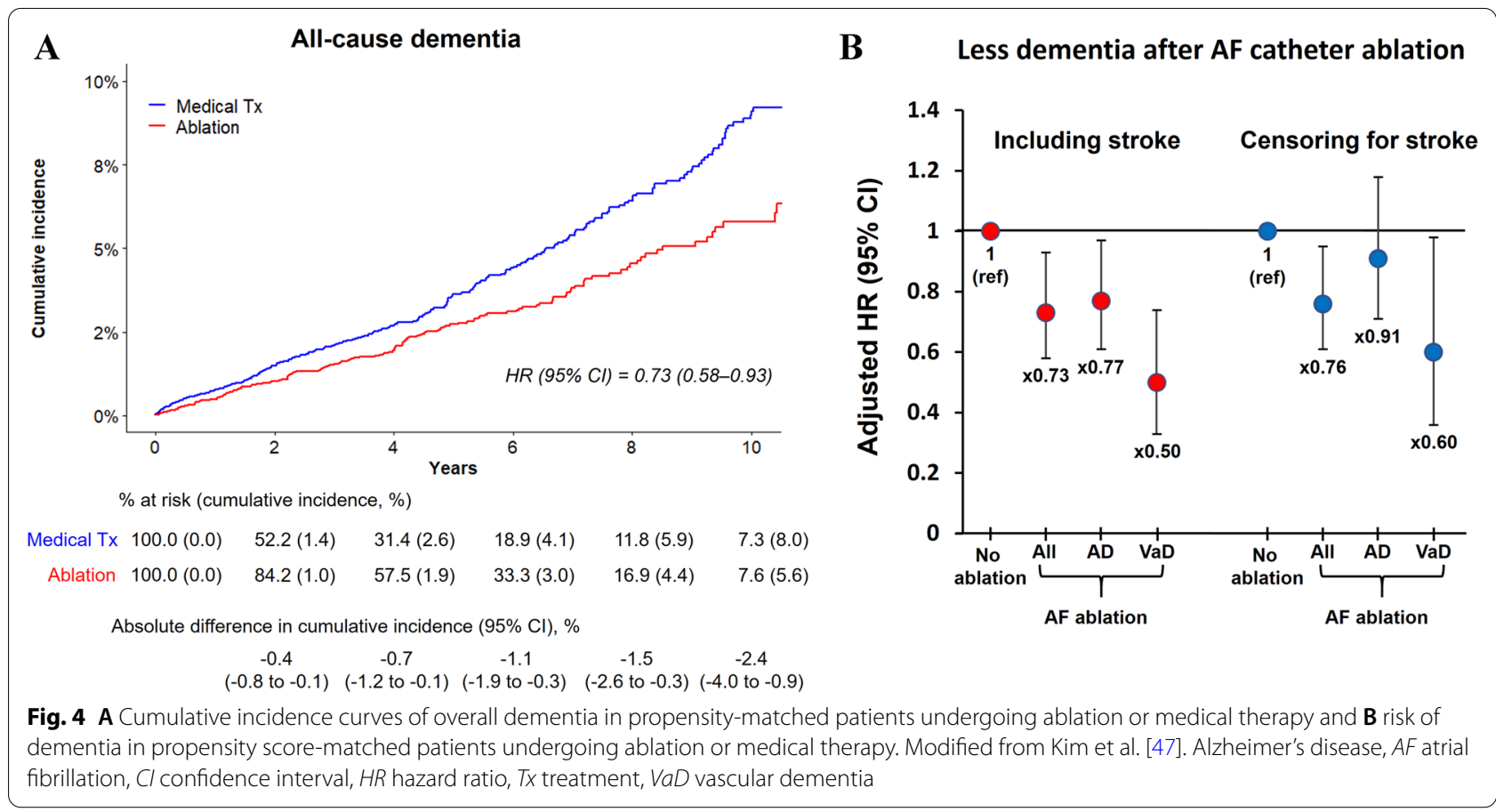

\section{Lower risk of dementia with catheter ablation}

Relationship between cognitive function and AF ablation

There is a peri-procedural stroke risk as well as a risk of silent ischemic brain lesions without corresponding neurological symptoms among patients undergoing ablation for AF $[37,38]$. However, a direct association of silent cerebral embolism with a decline in neurocognitive function is unproven [39], and many will resolve to the point of being undetectable after weeks or months. The AXAFA-AFNET 5 study comparing apixaban and warfarin in patients undergoing AF ablation reported that acute small brain lesion were found using a highresolution brain magnetic resonance imaging in 20-30\% of patients undergoing a first ablation. Interestingly, the same study found an improved cognitive function as measured by Montreal Cognitive Assessment (MoCA) at 3 months after ablation compared to baseline [40]. In line with this result, a recent prospective study by Jin et al. demonstrated an improvement of MoCA scores assessed 1 year after ablation [41].

\section{$\mathrm{AF}$ ablation might reduce the risk of dementia}

A previous study by Friberg et al. showed AF ablation might be associated with lower incidence of ischemic stroke, especially in patients with higher thromboembolic risk [42]. By reducing AF burden and subsequent atrial reverse remodeling [43], AF ablation may reduce silent cerebral infarcts and potentially improve perfusion of the brain. However, neither CABANA nor
CASTLE-AF reported cognitive outcomes [44, 45]. Bunch et al. reported patients ablated for AF have a significantly lower risk of dementia in comparison with age-/gender-matched AF patients without ablation [46].

Using a Korean nation-wide cohort, Kim et al. compared the risk of dementia between 9119 patients undergoing ablation and 17,978 patients managed with medical therapy therapy (antiarrhythmic or rate control drugs) [47]. During a median follow-up of 52 months, compared to patients with medical therapy, ablated patients showed a $27 \%$ reduced risk of overall dementia (Fig. 4). Ablation was associated with lower risk of both Alzheimer's disease and vascular dementia. Interestingly, the protective effect of ablation against dementia was strongly observed for the ablation success group, in whom the sinus rhythm was likely maintained. The authors inferred that the restoration of sinus rhythm, not the ablation procedure itself, was the important mechanism. However, in the claim-based database the study used, repeated ablation, cardioversion, and antiarrhythmic drug use were the only indices of post-ablation AF recurrences; thus, the actual burden of AF and its impact on cognitive dysfunction was unknown. The findings from an observational study cannot be used to establish causal relationships and residual confounding is likely to persist even after propensity score matching and weighting used in the study. It was impossible to determine the exact reasons for undergoing catheter ablation instead of medical treatment, which may introduce potential bias, and the potential remains 
for unmeasured confounders to have influenced the findings. Catheter ablation to reduce or eliminate AF should be further evaluated with a randomized-controlled trial with accurate determination of the residual burden of AF and specific measures of cognitive function [48].

\section{Conclusions}

Incident AF has been linked to an increased risk of cognitive dysfunction and dementia, independent of clinically overt stroke, suggesting that silent cerebral infarcts may contribute to the AF-related cognitive decline. Unfortunately, there are no randomized data examining the efficacy of various therapies or of individualized management in preventing dementia in individuals with AF. Accumulating evidence suggests that OAC use was related to a decreased incidence of dementia. In particular, NOAC use was associated with a reduced risk of dementia compared with warfarin. Successful catheter ablation well maintaining sinus rhythm might be helpful in preventing dementia in patients with $\mathrm{AF}$.

\section{Abbreviations}

AF: Atrial fibrillation; OAC: Oral anticoagulant; HR: Hazard ratio; MoCA: Montreal Cognitive Assessment; NOAC: Non-vitamin K antagonist oral anticoagulant; TTR: Time in therapeutic range.

\section{Authors' contributions}

All authors read and approved the final manuscript.

\section{Funding}

This study was supported by a research Grant from the Korean Healthcare Technology R\&D Project funded by the Ministry of Health \& Welfare (HI15C1200, HC19C0130).

\section{Declarations}

\section{Competing interests}

The authors declare no financial conflicts of interest.

\section{Author details}

${ }^{1}$ Division of Cardiology, Department of Internal Medicine, Severance Cardiovascular Hospital, Yonsei University College of Medicine, 50-1 Yonsei-ro, Seodaemun-gu, Seoul 03722, Republic of Korea. ${ }^{2}$ Department of Cardiology, CHA Bundang Medical Center, CHA University, Seongnam, Republic of Korea.

Received: 8 June 2021 Accepted: 1 August 2021

Published online: 24 September 2021

\section{References}

1. Joung B, Lee JM, Lee KH, Kim TH, Choi EK, Lim WH, et al. Korean guideline of atrial fibrillation management. Korean Circ J. 2018;48(12):1033-80.

2. Lee H, Kim TH, Baek YS, Uhm JS, Pak HN, Lee MH, et al. The trends of atrial fibrillation-related hospital visit and cost, treatment pattern and mortality in Korea: 10-year nationwide sample cohort data. Korean Circ J. 2017;47(1):56-64.

3. Kim D, Yang PS, Jang E, Yu HT, Kim TH, Uhm JS, et al. Increasing trends in hospital care burden of atrial fibrillation in Korea, 2006 through 2015. Heart. 2018:104(24):2010-7.
4. Kim D, Yang PS, Jang E, Yu HT, Kim TH, Uhm JS, et al. 10-year nationwide trends of the incidence, prevalence, and adverse outcomes of nonvalvular atrial fibrillation nationwide health insurance data covering the entire Korean population. Am Heart J. 2018;202:20-6.

5. Wortmann M. Dementia: a global health priority - highlights from an ADI and World Health Organization report. Alzheimers Res Ther. 2012;4(5):40.

6. Patterson C. International AsD. World Alzheimer report 2018: Alzheimer's Disease International; 2018.

7. Bunch TJ, Weiss JP, Crandall BG, May HT, Bair TL, Osborn JS, et al. Atrial fibrillation is independently associated with senile, vascular, and Alzheimer's dementia. Heart Rhythm. 2010;7(4):433-7.

8. Kim D, Yang PS, Yu HT, Kim TH, Jang E, Sung JH, et al. Risk of dementia in stroke-free patients diagnosed with atrial fibrillation: data from a population-based cohort. Eur Heart J. 2019;40(28):2313-23.

9. Singh-Manoux A, Fayosse A, Sabia S, Canonico M, Bobak M, Elbaz A, et al. Atrial fibrillation as a risk factor for cognitive decline and dementia. Eur Heart J. 2017;38(34):2612-8

10. Ott A, Breteler MM, de Bruyne MC, van Harskamp F, Grobbee DE, Hofman A. Atrial fibrillation and dementia in a population-based study. Rotterdam Study Stroke. 1997;28(2):316-21.

11. Dublin S, Anderson ML, Haneuse SJ, Heckbert SR, Crane PK, Breitner JC, et al. Atrial fibrillation and risk of dementia: a prospective cohort study. J Am Geriatr Soc. 2011;59(8):1369-75.

12. Marengoni A, Qiu C, Winblad B, Fratiglioni L. Atrial fibrillation, stroke and dementia in the very old: a population-based study. Neurobiol Aging. 2011;32(7):1336-7.

13. Rastas S, Verkkoniemi A, Polvikoski T, Juva K, Niinisto L, Mattila K, et al. Atrial fibrillation, stroke, and cognition: a longitudinal population-based study of people aged 85 and older. Stroke. 2007;38(5):1454-60.

14. Dagres N, Chao TF, Fenelon G, Aguinaga L, Benhayon D, Benjamin EJ, et al. European Heart Rhythm Association (EHRA)/Heart Rhythm Society (HRS)/ Asia Pacific Heart Rhythm Society (APHRS)/Latin American Heart Rhythm Society (LAHRS) expert consensus on arrhythmias and cognitive function: what is the best practice? Europace. 2018;20(9):1399-421.

15. Gaita F, Corsinovi L, Anselmino M, Raimondo C, Pianelli M, Toso E, et al. Prevalence of silent cerebral ischemia in paroxysmal and persistent atrial fibrillation and correlation with cognitive function. J Am Coll Cardiol. 2013:62(21):1990-7.

16. de la Torre JC. Is Alzheimer's disease a neurodegenerative or a vascular disorder? Data, dogma, and dialectics. Lancet Neurol. 2004;3(3):184-90.

17. Han F, Ali Raie A, Shioda N, Qin ZH, Fukunaga K. Accumulation of betaamyloid in the brain microvessels accompanies increased hyperphosphorylated tau proteins following microsphere embolism in aged rats. Neuroscience. 2008;153(2):414-27.

18. Reitz C, Tang MX, Schupf N, Manly JJ, Mayeux R, Luchsinger JA. A summary risk score for the prediction of Alzheimer disease in elderly persons. Arch Neurol. 2010;67(7):835-41.

19. Chopard R, Piazza G, Gale SA, Campia U, Albertsen IE, Kim J, et al. Dementia and atrial fibrillation: pathophysiological mechanisms and therapeutic implications. Am J Med. 2018;131(12):1408-17.

20. Vermeer SE, Prins ND, den Heijer T, Hofman A, Koudstaal PJ, Breteler MM. Silent brain infarcts and the risk of dementia and cognitive decline. $\mathrm{N}$ Engl J Med. 2003;348(13):1215-22.

21. Friberg $L$, Rosenqvist $M$. Less dementia with oral anticoagulation in atrial fibrillation. Eur Heart J. 2018;39(6):453-60.

22. Friberg $L$, Andersson T, Rosenqvist M. Less dementia and stroke in low-risk patients with atrial fibrillation taking oral anticoagulation. Eur Heart J. 2019:40(28):2327-35.

23. Mongkhon P, Fanning L, Lau WCY, Tse G, Lau KK, Wei L, et al. Oral anticoagulant and reduced risk of dementia in patients with atrial fibrillation: A population-based cohort study. Heart Rhythm. 2020;17(5 Pt A):706-13.

24. Flaker GC, Pogue J, Yusuf S, Pfeffer MA, Goldhaber SZ, Granger CB, et al. Cognitive function and anticoagulation control in patients with atrial fibrillation. Circ Cardiovasc Qual Outcomes. 2010:3(3):277-83.

25. Jacobs V, Woller SC, Stevens S, May HT, Bair TL, Anderson JL, et al. Time outside of therapeutic range in atrial fibrillation patients is associated with long-term risk of dementia. Heart Rhythm. 2014;11(12):2206-13.

26. Madhavan M, Hu TY, Gersh BJ, Roger VL, Killian J, Weston SA, et al. Efficacy of warfarin anticoagulation and incident dementia in a communitybased cohort of atrial fibrillation. Mayo Clin Proc. 2018;93(2):145-54. 
27. Lovelock CE, Cordonnier C, Naka H, Al-Shahi Salman R, Sudlow CL, Sorimachi T, et al. Antithrombotic drug use, cerebral microbleeds, and intracerebral hemorrhage: a systematic review of published and unpublished studies. Stroke. 2010;41(6):1222-8.

28. van Norden AG, van den Berg HA, de Laat KF, Gons RA, van Dijk EJ, de Leeuw FE. Frontal and temporal microbleeds are related to cognitive function: the Radboud University Nijmegen Diffusion Tensor and Magnetic Resonance Cohort (RUN DMC) Study. Stroke. 2011;42(12):3382-6.

29. Ruff CT, Giugliano RP, Braunwald E, Hoffman EB, Deenadayalu N, Ezekowitz MD, et al. Comparison of the efficacy and safety of new oral anticoagulants with warfarin in patients with atrial fibrillation: a meta-analysis of randomised trials. Lancet. 2014;383(9921):955-62.

30. Wang KL, Lip GY, Lin SJ, Chiang CE. Non-vitamin K antagonist oral anticoagulants for stroke prevention in asian patients with nonvalvular atria fibrillation: meta-analysis. Stroke. 2015;46(9):2555-61.

31. Chen N, Lutsey PL, MacLehose RF, Claxton JS, Norby FL, Chamberlain AM, et al. Association of oral anticoagulant type with risk of dementia among patients with nonvalvular atrial fibrillation. J Am Heart Assoc. 2018;7(21):e009561.

32. Jacobs V, May HT, Bair TL, Crandall BG, Cutler MJ, Day JD, et al. Longterm population-based cerebral ischemic event and cognitive outcomes of direct oral anticoagulants compared with warfarin among long-term anticoagulated patients for atrial fibrillation. Am J Cardiol. 2016:118(2):210-4.

33. Sogaard M, Skjoth F, Jensen M, Kjaeldgaard JN, Lip GYH, Larsen TB, et al. Nonvitamin K antagonist oral anticoagulants versus warfarin in atrial fibrillation patients and risk of dementia: a nationwide propensityweighted cohort study. J Am Heart Assoc. 2019;8(11):e011358.

34. Zhang C, Gu ZC, Shen L, Pan MM, Yan YD, Pu J, et al. Non-vitamin K antagonist oral anticoagulants and cognitive impairment in atrial fibrillation: insights from the meta-analysis of over 90,000 patients of randomized controlled trials and real-world studies. Front Aging Neurosci. 2018:10:258.

35. Kim D, Yang PS, Jang E, Yu HT, Kim TH, Uhm JS, et al. Association of anticoagulant therapy with risk of dementia among patients with atrial fibrillation. Europace. 2021;23(2):184-95.

36. Kim D, Yang PS, Jang E, Tae YuH, Kim TH, Uhm JS, et al. Blood pressure control and dementia risk in midlife patients with atrial fibrillation. Hypertension. 2020;75(5):1296-304.

37. Haeusler KG, Kirchhof P, Endres M. Left atrial catheter ablation and ischemic stroke. Stroke. 2012;43(1):265-70.
38. Nakamura T, Okishige K, Kanazawa T, Yamashita M, Kawaguchi N, Kato $\mathrm{N}$, et al. Incidence of silent cerebral infarctions after catheter ablation of atrial fibrillation utilizing the second-generation cryoballoon. Europace. 2017;19(10):1681-8.

39. Deneke T, Jais P, Scaglione M, Schmitt R, Di Biase L, Christopoulos G, et al. Silent cerebral events/lesions related to atrial fibrillation ablation: a clinical review. J Cardiovasc Electrophysiol. 2015;26(4):455-63.

40. Kirchhof P, Haeusler KG, Blank B, De Bono J, Callans D, Elvan A, et al. Apixaban in patients at risk of stroke undergoing atrial fibrillation ablation. Eur Heart J. 2018;39(32):2942-55.

41. Jin MN, Kim TH, Kang KW, Yu HT, Uhm JS, Joung B, et al. Atrial fibrillation catheter ablation improves 1-year follow-up cognitive function, especially in patients with impaired cognitive function. Circ Arrhythm Electrophysiol. 2019;12(7):e007197.

42. Friberg L, Tabrizi F, Englund A. Catheter ablation for atrial fibrillation is associated with lower incidence of stroke and death: data from Swedish health registries. Eur Heart J. 2016;37(31):2478-87.

43. Goette A, Kalman JM, Aguinaga L, Akar J, Cabrera JA, Chen SA, et al. EHRA/HRS/APHRS/SOLAECE expert consensus on atrial cardiomyopathies: definition, characterization, and clinical implication. Europace. 2016;18(10):1455-90

44. Packer DL, Mark DB, Robb RA, Monahan KH, Bahnson TD, Poole JE, et al. Effect of catheter ablation vs antiarrhythmic drug therapy on mortality, stroke, bleeding, and cardiac arrest among patients with atrial fibrillation: The CABANA randomized clinical trial. JAMA. 2019;321(13):1261-74.

45. Marrouche NF, Brachmann J, Andresen D, Siebels J, Boersma L, Jordaens $\mathrm{L}$, et al. Catheter ablation for atrial fibrillation with heart failure. N Engl J Med. 2018;378(5):417-27.

46. Bunch TJ, Crandall BG, Weiss JP, May HT, Bair TL, Osborn JS, et al. Patients treated with catheter ablation for atrial fibrillation have long-term rates of death, stroke, and dementia similar to patients without atrial fibrillation. J Cardiovasc Electrophysiol. 2011;22(8):839-45.

47. Kim D, Yang PS, Sung JH, Jang E, Yu HT, Kim TH, et al. Less dementia after catheter ablation for atrial fibrillation: a nationwide cohort study. Eur Heart J. 2020;41(47):4483-93.

48. Camm AJ. Does ablation of atrial fibrillation reduce the likelihood of dementia? A step closer but not yet there. Eur Heart J. 2020:41(47):4494-6.
Ready to submit your research? Choose BMC and benefit from:

- fast, convenient online submission

- thorough peer review by experienced researchers in your field

- rapid publication on acceptance

- support for research data, including large and complex data types

- gold Open Access which fosters wider collaboration and increased citations

- maximum visibility for your research: over $100 \mathrm{M}$ website views per year

At $\mathrm{BMC}$, research is always in progress.

Learn more biomedcentral.com/submissions 